\title{
Efektifitas Teknik Distraksi Musik Klasik Mozart untuk Mengurangi Nyeri pada Pasien Post Operasi Fraktur
}

\author{
Fitra Mayenti ${ }^{1,}$ Yusnita Sari ${ }^{2}$ \\ ${ }^{1,2}$ Program Studi Keperawatan Sekolah Tinggillmu Kesehatan Al Insyirah Pekanbaru \\ Email : fitramayenti19@gmail.com
}

Submitted : 03/02/2020

Accepted: 06/02/2020

Published: 14/03/2020

\begin{abstract}
Most fractures are caused by traffic accidents with an estimated number of fractures in the world between 1 and 2.9 million with different age classifications. Each fracture will always undergo surgery followed by administering analgesics to reduce pain during the surgery. Nonpharmacological management to deal with pain consists of various physical treatment measures including skin stimulus, electrical nerve stimulation of the skin, acupuncture. The purpose of the study was to assess the effect of giving classical music mozart in reducing fracture pain in the Dahlia Room of ArifinAchmad Hospital Pekanbaru. Quasy Experiment Research Design, non randomized control group pretest postest design. The research sample was 30 respondents, with a sampling technique accidental sampling. The study was analyzed univariately and bivariately with the Wilcoxon and Man Whitney test. Testing the reduction in the degree of fracture pain in the control and experimental groups obtained the mean value of the experiment 6.71 post experiment 2.66 control value pre 6.35 and control post 6.48 with a value of $\rho$ value 0.000 means that there is an influence of giving classical music mozart to fracture pain. Hopefully it can be used as a reference in providing mozart classical music distraction techniques to reduce pain in postoperative fracture patients.
\end{abstract}

Keyword: mozart music classic therapy, pain post operation

\begin{abstract}
Abstrak
Fraktur kebanyakan disebabkan oleh kecelakaan lalulintas dengan perkiraan jumlah fraktur didunia antara 1 sampai 2.9 juta dengan klasifikasi umur yang berbeda. Setiap fraktur akan selalu menjalani pembedahan dilanjutkan dengan pemberian analgesik untuk mengurangi nyeri saat proses pembedahan. Manajemen nonfarmakogis untuk mengatasi nyeri terdiri dari berbagai tindakan penanganan fisik meliputi stimulus kulit, stimulus elektrik saraf kulit, akupuntur.Tujuan penelitian menilai pengaruh pemberian music klasik Mozart dalam mengurangi nyeri fraktur diRuang Dahlia RSUD ArifinAchmadPekanbaru.Desain Penelitian Quasy Eksperimen, rancangannon randomized control group pretest postest design. Sampel penelitian sebanyak 30 responden, dengan teknik pengambilan sample accidental sampling.Penelitian dianalisis secara univariat dan bivariate dengan uji Wilcoxon danUji Man Whitney.Pengujian penurunan derajat nyeri fraktur pada kelompokkontrol dan eksperimen didapatkan nilai mean eksperimen pre 6.71 eksperimen post 2.66 nilai kontrol pre 6.35 dan kontrol post 6.48 dengan nilai $\rho$ value 0.000 artinya ada pengaruh pemberian music klasik Mozart terhadap nyeri fraktur. Diharapkan dapat sebagai acuan dalam memberikan teknik distraksi music klasik Mozart untuk mengurangi nyeri pada pasien post operasi fraktur.
\end{abstract}

Kata kunci : nyeri post operasi, terapi music klasik mozart

\section{PENDAHULUAN}

Fraktur merupakan diskontinuitas tulang yang bisa disebabkan karena trauma dan non trauma. Hal ini berdasarkan pendapat para ahli seperti Smeltzer\& Bare (2012) fraktur adalah terputusnya kontiunitas tulang dan ditentukan sesuai dengan jenisnya. Fraktur terjadi jika tulang dikenai stres yang lebih besar dari yang dapat di absorbsinya.

The National Center for Health Statistic (NCHS) melakukan riset dan menyebutkan bahwa di United Stated dalam waktu satu tahun terdapat 1,3 juta pasien 
fraktur yang mendapatkan perawatan di rumah sakit dan hampir 7000 pasien meninggal dunia (Michelle, 2010).

Fraktur merupakan kejadian terbanyak di RSUD Arifin Achmad di Ruang Dahliabagian didapatkan data dari Medical Record (RM) tiga tahun terakhir kejadian fraktur pada tahun 2014 sebanyak 303 kejadian, tahun 2015 terdapat 208 kejadian dan pada tahun 2016 selama 4 bulan dari Januari-April sebanyak 114 kejadian.

Setiap fraktur akan selalu menjalani pembedahan dilanjutkan dengan pemberian analgesik untuk mengurangi nyeri saat proses pembedahan. Pada saat masa kerja analgesik selesai, pasien akan mengeluhkan rasa nyeri. Hal ini dibuktikan dengan banyak pasien yang masih mengeluh nyeri meskipun sudah mendapatkan terapi analgesik (Darsono, 2011). Rasa nyeri yang dirasakan pasien dengan keluhan tersebut sebenarnya wajar karena tubuh mengalami luka dan poses penyembuhannya tidak sempurna. Secara signifikan nyeri dapat memperlambat pemulihan (Potter \& Perry, 2006).

Secara garis besar ada dua manajemen untuk mengatasi nyeri yaitu manajemen farmakologi dan manajemen non farmakologi.Manajemen farmakologis yang biasa digunakan adalah analgetik golongan opioid, tujuan pemberian opioid adalah untuk meredakan nyeri.(Smeltzer \& Bare, 2003).Manajemen non farmakologis untuk mengatasi nyeri terdiri dari berbagai tindakan penanganan fisik meliputi stimulus kulit, stimulus elektrik saraf kulit, akupuntur (Tamsuri, 2007).

Distraksi merupakan suatu tindakan pengalihan perhatian ke hal-hal lain diluar nyeri agar pasien tidak terlalu fokus terhadap nyeri (Andarmoyo 2013).Distraksi musik dapat mengalihkan perhatian dari rasa nyeri sehingga seseorang merasa rileks (Marmi 2012).Salah satu tindakan non farmakologis adalah dengan pemberian terapi musik yang dapat menurunkan nyeri fisiologis, dengan mengalihkan perhatian seseorang dari nyeri.Musik yang sejak awal sesuai dengan suasana hati individu, merupakan pilihan yang paling baik (Potter \& Perry, 2006).Terapi musik klasik dapat merangsang tubuh mengeluarkan opoid endogenyaitu endorfindan enkefalinyang memiliki sifat seperti morfinyaitu untuk mengurangi nyeri (Huges 1975 dalam Ernawati dkk 2010).

Salah satu musik klasik yang banyak digunakan dalam penelitian adalah musik klasik karya Mozart. Musik klasik karya Mozart ini selain merangsang kecerdasan dan merangsang kinerja otak kanan, juga merangsang neural plasticity (Yuwantari, 2011). Musik klasik mozart juga mempunyai struktur musik sesuai dengan pola sel otak manusia (Wirasti, 2011).

\section{METODE PENELITIAN}

Jenis penelitian ini adalah kuantitatif dengan desain penelitian ini adalah quasy experiment design dengan rancangan non randomized control group pretest postest design. Tenik pengambilan sampel pada penelitian ini adalah accidental sampling.Penelitian ini dilakukan dari tanggal 1 sampai 10 Maret 2017 di Ruang Dahlia RSUD Arifin Achmad Pekanbaru dengan responden pasien post operasi fraktur.Sampel yang digunakan sebanyak 30 orang dengan 15 kelompok kontrol dan 15 kelompok eksperimen dengan instrumen NRS (Numeric Rating Scale).Analisa data yang diguanakan adalah analisa data univariat dan bivariat.

\section{HASIL DAN PEMBAHASAN}

Berdasarkan tabel 1 menunjukan bahwa karakterisitik responden dari 30 responden yang diteliti berdasarkan kategori umur terdapat mayoritas umur respoden adalah dewasa sebanyak 23 orang (76.7\%) sedangkan untuk jenis kelamin mayoritas adalah laki-laki sebanyak 20 orang $(66.3 \%)$. 
Tabel 1 Karakteristik Responden Berdasarkan Kategori Umur dan Jenis Kelamin di Ruang Dahlia RSUD Arifin Achmad Pekanbaru

\begin{tabular}{|c|c|c|}
\hline Karakteristik & $\mathbf{f}$ & $\%$ \\
\hline \multicolumn{3}{|l|}{ Umur } \\
\hline Remaja & 3 & 10.0 \\
\hline Dewasa & 23 & 76.7 \\
\hline Lansia & 4 & 13.3 \\
\hline Total & 30 & 100 \\
\hline \multicolumn{3}{|l|}{ Jenis kelamin } \\
\hline Laki - laki & 20 & 66.7 \\
\hline Perempuan & 10 & 33.3 \\
\hline Total & 30 & 100 \\
\hline $\begin{array}{l}\text { Beberapa } \\
\text { bahwa usia de } \\
\text { yang merupaka } \\
\text { dan cenderung } \\
\text { aktifitas yang ti }\end{array}$ & $\begin{array}{l}\mathrm{h} \mathrm{d} \\
\text { ia } \mathrm{p}\end{array}$ & $\begin{array}{l}\text { atakan } \\
\text { duktif } \\
\text { g aktif } \\
\text { karena }\end{array}$ \\
\hline
\end{tabular}

Tabel 2 Rata-rata Nilai Derajat Nyeri Pada Kelompok Kontrol Dan Eksperimen Yang Diukur Pada Saat Pretest Dan Posttest di Ruang Dahlia RSUD Arifin Achmad Pekanbaru

\begin{tabular}{lcccc}
\hline \multicolumn{1}{c}{ Variabel } & Mean & SD & Min & Max \\
\hline $\begin{array}{l}\text { Rata-rata } \\
\text { nyeri } \\
\text { fraktur }\end{array}$ & & & & \\
pretest & & & & \\
Eksperimen & 6.71 & 0.53 & 5.66 & 7.66 \\
\hline Kontrol & 6.35 & 0.68 & 5.33 & 7.66 \\
\hline $\begin{array}{l}\text { Rata-rata } \\
\text { nyeri }\end{array}$ & & & & \\
$\begin{array}{l}\text { fraktur } \\
\text { posttest }\end{array}$ & & & & \\
Eksperimen & 2.66 & 0.69 & 1.33 & 3.66 \\
\hline Kontrol & 6.48 & 0.66 & 5.66 & 7.66 \\
\hline
\end{tabular}

Dari tabel 2 menunjukanbahwa pada kelompok eksperimen pretest dengan mean 6.71 dengan standar deviasinya 0.53 sedangkan pada eksperimen posttest dengan mean 2.66 dan standar deviasinya 0.69. Pada kelompok kontrol pretest dapat dilihat nilai mean 6.35 dengan standar deviasinya 0.68 sedangkan pada kontrol posttest dengan mean 6.48 dengan standar deviasinya 0.66 .
Tabel 3 Distirbusi penurunan derajat nyeri Pada Kelompok Kontrol Dan Eksperimen Yang Diukur Pada Saat Pretest Dan Posttest di Ruang Dahlia RSUD ArifinAchmad Pekanbaru

\begin{tabular}{|c|c|c|c|c|}
\hline Variabel & $\begin{array}{l}\text { Mea } \\
\mathrm{n}\end{array}$ & SD & $\mathrm{N}$ & $\mathrm{P}$ \\
\hline $\begin{array}{l}\text { Rata-rata nyeri post } \\
\text { operasi fraktur } \\
\text { kelompok kontrol } \\
\text { Kelompok Kontrol } \\
\text { pre }\end{array}$ & 6.35 & 0.68 & 30 & $\begin{array}{c}0.12 \\
9\end{array}$ \\
\hline $\begin{array}{l}\text { Kelompok Kontrol } \\
\text { post }\end{array}$ & 6.48 & 0.66 & & \\
\hline $\begin{array}{l}\text { Rata-rata nyeri post } \\
\text { operasi fraktur } \\
\text { kelompok } \\
\text { eksperimen } \\
\text { Kelompok } \\
\text { Eksperimen pre }\end{array}$ & 6.71 & 0.53 & 30 & $\begin{array}{c}0.00 \\
0\end{array}$ \\
\hline $\begin{array}{l}\text { Kelompok } \\
\text { Eksperimen post }\end{array}$ & 2.66 & 0.69 & & \\
\hline
\end{tabular}

BerdasarkanTabel 3 menunjukan bahwa pada kelompok kontrol pre dengan standar deviasi 0.68 dan kontrol post dengan standar deviasi 0.66 dan Pvalue untuk kelompok kontrol 0.129 yang berarti $\mathrm{P}$ value $>0.05$. Sedangkan pada kelompok eksperimen pre denganstandar deviasi 0.53 dan eksperimen post dengan standar deviasi 0.69 dan $\mathrm{P}$ value 0.000 yang berarti $\mathrm{P}$ value $<0,05$ sehingga dapat disimpulkan adanya perbedaan signifikan antara kelompok kontrol dan eksperimen setelah dibei perlakuan.

Penurunan nyeri menggunakan musik sangat efektif karena musik dapat melakukan pengalihan perhatian dan kecemasan yang dapat meningkatkan intensitas nyeri yang dirasakan pasien, dengan mendengarkan musik otak merangsang pelepasan endoprin yang berfungsi untuk menurunkan nyeri yang dirasakan pada bagian tubuh yang sakit.

Hal ini sesuai penelitian yang dilakukan oleh Dian Novita (2012) di RSUD DR. H. Abdul Moeloek Provinsi Lampung hasil uji menunjukan adanya perbedaan signifikan antara rata-rata kelompok kontrol dan kelompok intervensi 
dengan 36 responden yang didapat yaitu kelompok kontrol adalah 683. Sementara rata-rata tingkat nyeri pada kelompok intervensi yaitu 4.89.

Berdasarkan penelitian yang dilakukan oleh Muhammad Firdaus (2014) di RSUD Arifin Achmad Pekanbaru dengan sampel 30 orang hasil uji statistik didapatkan nilai $\mathrm{p}=0,000$ dengan alpha 0,05 maka dapat didapatkan ada perbedaan yang signifikan antara tingkat nyeri pada kelompok kontrol dan kelompok eksperimen.

Selain itu penelitian yang dilakukan Rivaldy Djamal (2015) di Irina A RSUP Prof. DR. R.D. Kandou Manado. Hasil uji $\mathrm{T}$ didapat nilai $\mathrm{P}$ value $=0,000$ dengan $\alpha=$ 0,05 sehingga disimpulkan bahwa terdapat perngaruh musik terhadap nyeri pada pasien post operasi fraktur.

Berdasarkan penelitian yang dilakukan oleh Resa Nirmala Jona tantang perbedaan efektivitas teknik relasksasi nafas dalam dan terapi musik klasik terhadap intensitas nyeri pada pasien yang mengalami fraktur dengan nyeri sedang di RSUD Dr. H. Soewondo Kendal (2013) dengan responden sebanyak 22 orang didapatkan bahwa 16 responden $(72,72 \%)$ mengalami penurunan skala nyeri. Hasil uji mann whitney menunjukan nilai $\mathrm{p}=0,213$ $(\mathrm{p}>0,05)$ sehingga dapat disimpulkan bahwa tidak ada perbedaan efektifitas teknik relaksasi nafas dalam dan terapi musik klasik terhadap intensitas nyeri pada pasien yang mengalami fraktur dengan nyeri sedang.

Musik bekerja pada sistem syaraf otonom yaitu bagian sistem saraf yang bertanggung jawab mengontrol tekanan darah, denyut jantung, fungsi otak, mengontrol perasaan dan emosi.Mendengarkan musik dengan penuh rileksasi dapat mengurangi nyeri karena merangsang keluarnya hormnon endorphin dari dalam tubuh sebagai morphin alami.Dengan mendengarkan musik tersebut dapat sebagai penyembuh alami, penyeimbang produksi hormon tubuh dan penyegaran pikiran dari kecemasan yang dapat menyebabkan meningkatnya rasa nyeri dari tubuh.Pada umumnya musik juga sangat dekat dengan kehidupan sehari-hari dan akrab terdengar oleh telinga manusia, musik juga dapat mengekspresikan perasaan dan dapat mengalihkan perhatian yang terfokus.Musik juga sangat berperan dalam kesehatan yaitu sebagai media distraksi untuk terapi seperti nyeri, kecemasan dan lainnya.

Musik dapat mempengaruhi otak, hubungan saling mempengaruhi ini terutama diproses oleh komponen otak yang terletak ditengah otak bernama limbik.Inilah pusat emosi dari seluruh makhluk mamlia yang memungkinkan seseorang individu melihat bmasalah tidak saja dari satu sudut, yaknni rasionalitas, tetapi juga melihatnya dengan pendekatan emosi dan intuisi (termasuk sense of art).Tidak mengherankan, setiap musik yang menyentuh sistem limbik akan dirasakan sama manusia dan hewan, karena sistem limbik ini merupakan komponen yang juga berkembang baik pada hewan (Pasiak, 2007).

Menurut Jensen (dalam Pasiak, 2007), pengaruh musik terhadap tubuh antara lain (1) meningkatkan energi otot, meningkatkan energi molekul, mempengaruhi denyut jantung, (4) mempengaruhi metabolisme, (5) meredakan nyeri dan stress, (6) mempercepat penyebuhan pasien pasca operasi, (7) meredakan kelelahan, (8) membantu melepaskan emosi yang tidak nyaman, (9) menstimulasi kreativitas, sensivitas, dan berpikir.

\section{SIMPULAN}

Rata rata derajat nyeri pada kelompok eksperimen sebelum diberi perlakuan adalah 6.71 dan sesudah diberikan perlakuan adalah 2.66 rata-rata nyeri pada kelompok kontrol sebelum adalah 6.35 
dengan nilai pada kelompok kontrol post yaitu6.48.

Ada pengaruh pemberian terapi musik klasik Mozart untuk mengurangi nyeri pada pasien post operasi di Ruang Dahlia RSUD Arifin Achmad Pekanbaru dengan P value $0.000<0.05$.

Berdasarkan hasil penelitian saran yang dapatdisampaikan peneliti yakni sebagai informasi dalam pelayanan kesehatan khususnya perawat RSUD Arifin Achmad tentang teknik distraksimusik klasik Mozart u ntuk mengurangi nyeri pada pasien post operasi fraktur dan sebagai bahan kajian pustaka serta studi banding untuk masalah yang sama dengan sampel yang berbeda. Bagi responden dapat menjadikan music klasik Mozart sebagai salah satu cara alternatif dalam terapi nonfarmakologi suntuk mengurangi nyeri tanpa harus menggunakan obat.

\section{DAFTAR PUSTAKA}

Alan Yanuar, Wantonoro. 2015. Pengaruh terapi music klasik terhadap intensitas nyeri pada pasien post operasi fraktur di RSU PKU Muhammadiyah Yogyakarta.Naskah publikasi.STIKES 'Aisyiyah Yogyakarta. Diakses pada tanggal 15 April 2016

Andarmoyo, Sulistyo. 2013. Konsepdan proses keperawatannyeri. Yogyakarta :Ar-Ruzz

Asmadi. 2008. Teknik procedural keperawatan konsep dan aplikasi kebutuhan dasar klien. Jakarta :Salemba Medika

Aziz Alimul, 2012. Pengatar kebutuhan dasar manusia, aplikasi konsep dan proses keperawatan. Jakarta :Salemba Medika

Barbara, Koizer. 2010. Buku ajar fundamental keperawatan, Vol. 2. Edisi 7.Jakarta : EGC

Biftah. 2015. Pengertian music klasik.http://biftah.com/pengertianmusik-klasik/. Diakses pada tanggal 13 Mei 2016
Campbell, Don. 2011. Efekmozart. Jakarta: PT GramediaPustaka

Darsono. 2011. Terbebasdarinyeri post operasi. Yogyakarta: Grahallmu

Djamal, Rivaldy. 2015. Pengaruhterapimusikterhadapskalanyer ipadapasienfraktur di IRINA A RSUP Prof. Dr. R. D. Kandou. Vol. 3 No. 2

Ernawati, HartatidanHadi. 2010. Terapi relaksasi terhadap nyeri disminore pada mahasiswi Universitas Muhammadiyah Semarang. $\quad$ http://jurnal.Unimus. ac.id/index.phppsn12012010/article/vie w/45Diakses pada tanggal 14 maret 2016

Firdaus, Muhammad, Dkk. 2014.Efektifitas terapi musik Mozart terhadap penurunan intensitas nyeri pada pasien post operasi fraktur ekstremitas bawah. Jurnal online mahasiswa PSIK. Vol. 1 No. 2

Hendra, A. 2010.Pengaruh pemberian music klasik terhadap prestasi belajar matematika anak. Soegijapianata :Fakultas Psikologi Universitas Katolik

Hockenberry, M., Wilson, D. 2013.Wong's Essentials of pediatric nursing.9th edition.USA : Elsevier

Jona, Dkk. 2013.Perbedaan efektifitas teknik relaksasi nafas dalam dan terapi musik klasik terhadap intensitas nyeripada pasien yang mengalami fraktur dengan nyeri sedang.Semarang. STIKES Telogorejo

Juniartha. 2007. Angka kejadian fraktur. http://okezone.comdiakses pada tanggal 3 Februari 2016

Koizer, B, Erb, G, Berman, A \& Snyder, SJ. 2010. Buku ajar fundamental keperawatan :konsep, proses \&praktik, edisi 7. Jakarta : EGC

Krebs, EE, Carey, TS \& Weinberger, M. 2007.Accuracy of the pain numeric rating scale as a screening test in primary care, Vol 22 No. 10

Kusumawati, Dewi. 2015. Penatalaksanaan nyeri pasca operasi. http://www.rssanto yusup.com/penatalaksanaan-nyeri- 
pasca-operasi/ Diakses pada tanggal 12 Maret 2016

Lefevre, Michelle. 2010. Communicating with cildren and young people: making a difference. Washington: Social Prentice Press

Lestari, Puji, Dkk. 2014.Efektifitas terapimusik terhadap skala nyeri pada pasien kanker payudara di RumahSakit Umum DR. H Soewondo Kendal.Semarang: STIKES Telogorejo Semarang. http://pmb.stikestelorejo. ac.id/ejournal/index.php/ilmukeperawa tan/article/view/235.Diakses pada tanggal 12 April 2016

Lukman\&Ningsih N. 2011. Asuhan keperawatan pada klien dengan gangguan sistem muskuloskeletal. Jakarta :Salemba Medika

Marmi, D 2013.Intranatal care asuhan kebidanan pada persalinan.Yogyakarta :Pustaka Pelajar

Meara, John. 2013. Estimating the global incidence of femur fracture. Boston :American Public Health Association. Diakses pada tanggal 24 Mei 2016

Merrit, S. 2003. Simfoniotak.Bandung: PenerbitKaifa

Michelle, D. S. 2010. Making a point about open fractures, Volume 40 No 4

Notoadmojo, $\quad$ Soekidjo. 2012. Metodologipenelitiankesehatan. Jakarta :RinekaCipta Novita, Dian.

2012.

Pengaruhterapimusikterhadapnyeri post operasiopen reduction and internal fixation (ORIF) di RSUD Dr. H. Abdul Moeloek. Tesis.Lampung.Universitas Indonesia

Nurgiwiati, Endeh. 2015. Terapi alternative \& komplementer dalam bidang keperawatan.Bogor : In Media

Pasiak, T. 2007. Brain Management for Self Improvement.Bandung :Mizan

Potter \& Perry. 2006. Bukuajar fundamental keperawatan. Jakarta : EGC
2010. Bukuajar fundamental keperawatan. Jakarta :SalembaMedika

Prasetyo. 2010. Konsepdan proses keperawatan nyeri. Yogyakarta :GrahaIlmu

Reeves CJ, dkk. 2011. Keperawatan medikal bedah. Jakarta :Salemba Medika

RSUD Arifin Achmad. 2016. Laporan tahunan catatan medis/rekam medisRSUD Arifin Achmad Pekanbaru

Ruslan, Rosady. 2013. Metode penelitian: public relations dankomunikasi. Jakarta :RajawaliPers

Saryono. 2011. Metodologi penelitian kesehatan. Jogjakarta :Mitra Cendekia

Sjamsuhidajat\& De Jong. 2011. Buku ajar ilmu bedah. Edisi 3. Jakarta: EGC

Smeltzer\& Bare. 2012. Buku ajar keperawatan medika lbedah Brunner danSuddarth. Jakatra : EGC

Sugiono. 2009. Metode penelitian kuantitatif kulitatif. Bandung :Alfabeta

Sujarweni, Wiratna. 2014. Metodologi penelitian keperawatan. Yogyakarta :Gava Media

Syaiful,Yuanita\&SigitHendroRachmawan. 2014.Efektifitas relaksasi nafas dalam dan distraksi baca menurunkan nyeri pasca operas ipasien fraktur femur. Vol 5 No 2 November 2014

Tamsuri, A. 2007.Konsep dan penatalaksanaan nyeri. Jakarta: EGC

Yanuarita, F. A. 2012. Memaksimalkan otak melalui senamotak (brain gym). Yogyakarta :Teranova Books.

Yuwantari, Vina. 2011. Pengaruh music terhadap aktivitas Basolateralamyglasa dan hypothalamus. Skripsi Surabaya Universitas Airlangga 